\title{
The uses, benefits and limitations of social media for public relations in South African non-governmental organisations
}

\author{
M Nchabeleng \\ CJ Botha \\ CA Bisschoff
}

North-West University, South Africa

\begin{abstract}
Keywords
Twitter, Facebook, business relations, communication, NGOs.
\end{abstract}

\begin{abstract}
In South Africa, social media has become a popular public relations research topic in nongovernmental organisations (NGOs). This is because NGOs are increasingly integrating social media into their public relations strategies in an effort to engage with the variety of stakeholders by using communication platforms such as Facebook and Twitter that social life takes place, people communicate and share information. This study reviews the current uses, benefits, and limitations of social media in public relations among NGOs and analyses how South African public relations practitioners are experiencing these uses, benefits and limitations of social media in NGOs. Based on theoretical guidelines for social media public relations communication the empirical study employs a qualitative research using in-depth, semi-structured interviews with public relations practitioners in NGOs.

The results provide a holistic view of their experience in social media. The key benefits of using social media were identified as theincreasing public relations interactions with audience, improving the accessibility of public relations communication, increasing the speed for feedback and input, social/peer and emotional support, potential to influence the public, improving the long-term cost effective relationship of public relations communication, reaching youth and other audiences on specific issues. The limitations were identified as quality concerns, confidentiality and private information leaking to the public, and the reliability of information.
\end{abstract}

Corresponding author: CA Bisschoff

Email addresses for corresponding author: nchabelengmpumi@yahoo.com

First submission received: $3^{\text {rd }}$ May 2017

Revised submission received: 24 $4^{\text {th }}$ August 2017

Accepted: $16^{\text {th }}$ October 2017

Introduction

The Internetoriginated from the Cold War between the United States and the former Soviet Union during the 1960s as a strategic American defense advantage (Neuman 2010) and launched by the United States in 1969 as the Advanced Research Projects Agency Network (or as commonly know "ARPANET") (Kellerman 2014). This was a network that constituted an experimental, alternative communications system for telephone services, and it was developed for the potential replacement of the telephone system in case of nuclear war. White (2014:126) states that the history of the original internet designers was military based and initially intended to establish an advanced research project to give the freedom to develop innovative ideas. Kellerman (2014) adds to this view by stating that originally theInternet experimented through a network connecting security headquarters with universities, followed by the emergence of academic networks. The Internet has grown explosively, now reaching over a billion people, given a very generous definition of "reach" and changing the way we live and think (Neuman 2010:142). Graham and Dutton (2014) note that worldwide over 6 billion people are subscribers of wireless devices which means that humanity is almost fully connected.

The expansion of the Internet has been one of the most significant developments for media in the twenty-first century. The Internet has been fundamental to many new media, and the concept of "Web 2.0" suggests a second generation of the World Wide Web (Gorman and McLean 2009). The initial purpose of Internet was to provide a method of rapid information exchange for research and defense

www.jbrmr.com A Journal of the Academy of Business and Retail Management (ABRM) 
purposes (White 2014). The intention was to create a decentralised system of linked computers so that information could be re-routed if any part of the network was damaged or ceased to function (Gorman and McLean 2009:237).

Over the past years, there is an on-going increase in the use of social media locally and globally in the public relations practice. Social media is used to describe online tools and utilities that allow communication and information, participation and collaboration online and it is based on a group of internet based applications that build on the ideological and technological foundation of Web 2.0 and allow the creation of exchange (Kaplan and Haenlein 2010:61).The emergence of social media, including social networking technologies, has had a profound impact on public relations activities. (Social networking is the two-way directed communication that includes sharing of information among several parties.)In this regard, Graham and Dutton (2014) indicated that social networking sites had become the social spaces where people meet, socialise, retrieve information, express themselves, work, create, imagine, participate, fight and shape their experiences. The updated research by these authors confirm this growing trend in shared social behaviour and show that it expanded into various business functions such as communication, public relations, market information and other applications (Graham and Dutton 2017). In fact, Pindar (2017) projects further growth in business applications of social media in 2017, although it has already increased by $191 \%$ in 2016 alone.

\section{Literature review: public relations in social media}

It is important to note that social media differs from other public relations activities in two ways. Firstly, the speed of disseminating information is almost in real time, while secondly, the information is disseminated on a globalised scale. This has never before been possible.

Globalisation is defined by the Business Directory (2017) as "The worldwide movement toward economic, financial, trade, and communications integration". This definition indicates the shift towards a more integrated and independent world thereby merging historically distinct and separate markets into one huge global marketplace. The rise of the computer-mediated communication in the $21^{\text {st }}$ century, communication patterns have changed, and people have shifted from face-to-face, landline telephone, and postal communication to digital communication that enables users to stay online all the time. The explosion of wireless platforms in the last decade has distributed the power of the Internet everywhere (Graham and Dutton 2014; 2017). Wright (2014:7) also noted that social media is a new ever-evolving tool that can help expand our knowledge and our reach and help us innovate and collaborate in bold new ways, while Rettberg (2014) states that social media is mainstream that describes online many to many communication. Already in 2012, Al-Deen and Hendricks (2012) warned that it is impossible to ignore the influence of social media on our society. While it took traditional media such as radio and television more than a decade to reach 50 million users, it took Facebook less than nine months to reach 100 million users by the end of 2010 (Patel 2010). Facebook currently has 1.9 billion users across the world (Zuckerberg 2016 in CNN News 2017).

\section{Public relations}

Public relations are traditionally a marketing function resorting to the promotion function of the marketing mix. However, two clear distinctions from the other tools in the communication function of the marketing mix is that an organisation does not pay for public relations exposure and that public relations also includes information about the not-so-good incidents that happen at an organisation. British Petroleum's communication released by their public relations department after their oil spill in the Gulf of Mexico attests to also communicating bad news to the world (Smithsonian Museum of Natural History, 2010). Public relations then specifically refer to the "unpaid" communication of an organisation with its environment. More specifically, the Business Directory (2017) defines public relations as "The profession or practice of creating and maintaining the goodwill of an organization's various publics (customers, employees, investors, suppliers, and others), usually through publicity and other nonpaid forms of communication".

Public relations' use of technology and social media will continue to increase in the wake of the public's technological adoption. Before the advent of social media technologies, traditional media used to be the dominant vehicle for public relations practitioners. Since the rapid increase of new media 
technologies, social media have democratised communication landscape, making it possible for everyone to regardless of time and space, create and publish information (Graham and Dutton 2017).

\section{Social media}

An older definition of social media is "a group of new kinds of online media has six potential strengths; participation and engagement, openness, conversation, community, and connectedness" (Mayfield, 2008).

Later Graham and Dutton (2014:349) define social media as "possessing three characteristics: the affordance of user-generated content, the ability for individuals to directly engage with other individuals and content and the ability to select and articulate network connections with other individuals".

Seargeant and Tagg (2014:4) add their definition stating that "the essence of social media, as a focus on the facilitating of participation and interaction with the result that the content of what is developed and shared on the internet is as much a product of participation as it is of traditional creative and publishing/broadcast processes".

More recently the Business Directory (2017) defines social media as "Social media includes popular networking websites, like Facebook and Twitter; as well as bookmarking sites like Reddit. It involves blogging and forums and any aspect of an interactive presence which allows individuals the ability to engage in conversations with one another, often as a discussion over a particular blog post, news article, or event".

Another modern definition of social media is "the use of Information and Communication Technologies (ICT), such as Facebook, Twitter, and others, as a tool to achieve better communication." (Graham and Dutton 2017). Social media was enabled by the launch of the Web 2.0 software (social media is sometimes referred to as Web 2.0) which is characterised by the use of generated content, ability to engage with individuals and content directly and to select and articulate network connections. The kinds of Internet services commonly associated with social media include the Blogs, Wikis, Social Bookmarking, Social Networking sites, Virtual world content, and Media-sharing sites (O'Reilly 2005). Rathore (2016) states that Web 2.0 "allows users to collectively classify and find dynamic information that flows two ways between the site owner and site user using evaluation, comments, and reviews. Site users can add content for others to see". The key characteristic of Web 2.0 applications is that they allow and actively encourage user contribution, interaction and full production and distribution of user-generated content (Gorman and McLean 2009); these features have also been further developed to facilitate better information classification, rich user experience, user participation and trust (WebAppRater 2010). Although launched in 2008, Web 2.0 is still described as a "business revolution in the computer industry" (Rathore 2016). According to Seargeantand Tagg (2014:4), Web 2.0 indicates a new stage in the online development of the Web. The findings indicated new media makes it possible for everyone to create, modify and share content with others. New media removes many of the barriers of communication. Technology is fundamentally changing the way information is distributed, and that information flows in new ways, and social media has (and still is) changing the relationship between producers and consumers of the message. Social media also provide a way of keeping in touch with friends, relatives, and communities, and enable the sharing of experience because of its picture and video enabled characteristics.

Social media has particularly revolutionised the way in which people communicate with one another and share information. The dissemination of information is especially valuable in personal and business communication. Social media also provides opportunities for users to generate, share, receive and comment on social content, thereby facilitating two-way communication not possible with other media such as press releases, radio or television appearances. Some years ago Erasmus (2012) argued that little has originally been writtenin social media use and implementation. This is no longer the case. Some researchers now focus their studies to address this issue (Supa 2014; Patel 2016). However, there still seems to be a lack of empirical data on examining the impact of social media on public relations practice in NGOs, and especially so in South Africa.

On an organisational level, social media also allow organisations to reach large numbers of people. Social media is a powerful tool which offers collaboration between users. There was a noticeable improvement in online communication, however, public relations practitioners in NGO sector is still not transformed. Although online media is used and has increased there is still a long way to go before public relations communication is fully represented at management level. It is also important that the management in the South African NGO sector (and also public relations practitioners) embrace and 
incorporate social media into their communication strategies. In this regard, Nchabeleng (2016) indicated that although the use of social media in public relations has increased, the adoption of social media in NGOs is still very low. However, in the private sector social media has changed the way public relations operate. It has moved from the traditional top-down way of communicating to one where there is a twoway flow of communication. It is now also expected of public relations practitioners to actively engage with new media, and social media has become an integral part of their work. Social media has brought a transformation in the relationship between the public relations and their audience, but then this seems only to be true of the private sector. NGOs have not yet adopted the social media as active public relations tool. Against this background, it seems appropriate to formally study the uses, benefits, and limitations that social media applications have on public relations and communication in NGOs.

\section{Objective}

The objective of this studywas to review the current published literature to identify the uses, benefits and limitations of social media for public relations among the NGOs, to identify some theoretical guidelines for social media public relations communication based on the literature and to evaluate these guidelines empirically against the perspective held by South African NGOs.

\section{Research Methodology \\ Research settings and participants}

This study adopted a qualitative research design. The research setting was limited to the nine non-governmental organisations (NGOs) of varying sizes in Gauteng. According to Creswell (2013) in a grounded study the researcher chooses participants who can contribute to building the opening an axial coding of the theory. Emails were sent to the selected NGOs to gain permission to conduct research at the NGOs around Gauteng. The organisational setting differed from participant to participant. The qualitative data were collectedusing semi-structured individual interviews. Interviews were conductedface-to-face and technology devices were used to record the interviews so that no information losses would occur. The participants were informed of the confidential conversation and were asked permission before the interview was recorded. Because there is no prescriptive sample size for qualitative grounded theory studies, saturation was used to a guideline for the number of interviews. Here practitioners using social media as a public relations tool for communication in NGOs were selected because they are knowledgeable and able to provide accurate information. Saturation was based on judgement after taking into consideration the nature of the study, the selected NGOs, and the norms and culture of NGOs. Saturation was assumed when the last two interviewees failed to produce any new information and merely repeated what the other interviewees already stated in all the categories discussed. This meant that theoretical saturation was reached with nine participants in NGOs.

\section{Research process}

Before the interview, the researcher phoned and emailed participants an "Information and consent form "to be completed and returned either beforehand via email or in hard copy during their interview. This process ensured that the participants were informed about the interview and that the focus was on their individual in-organisation experiences and their perception on social media as public relations tool. Furthermore, the researcher reminded the participants that there was no wrong or right answer in this type of discussion and had to elaborate. The researcher engaged in a discussion and review of the data with the research supervisor.

\section{Results}

The results identified six key attributes of social media experienced by the public relations practitioners in the communication positions. These key attributes are:

- Social media provide information on a range of conditions (entertainment, safety, work conditions, newsworthy events and others) to the public;

- Social media communication can provide answers to NGO questions;

- Social media can instantly supply and update information on a wide range;

- Facebook is used by the public to share experience;

- Social media allow increasing the speed of stakeholder feedback and input; and 
- Social media can be used to collect data on donors, and it can also be used for promotion, education and to raiseawareness in communities.

The study also aimed to identify the specific benefits social media could have for NGOs if they would engage social media as public relations tool. The three benefits that were identified by the interviewees were:

- Increasing NGOs' access to the public especially the youth;

- Improving the long-term costeffectiveness of public relations communication in NGOs; and

- An important aspect of using social media for NGOs is that it can provide valuable peer, social and emotional support for the communities and the public.

From these results it is evident that with the proliferation of media and all the new and different media platforms, social media has changed public relations strategy to put the NGO activities at the centre with all the extension around it, events, campaigns to name but a few, all form part of promoting the NGO. In addition to the attributes and benefits the use of social media could render as public relations tool, the interview data furthermore also identified four distinct attribute categories (Global perspective, Uses of social media, Benefits of social media and Limitations)to consider when using social media for public relations. Supporting themes for each of these considerations were developed. These considerations, as experienced by the NGOs' public relations practitioners in using social media for communication, are discussed and tabularised below.

\section{Global perspective}

Both the literature and empirical findings show the attributes that can affect the way people interact online and that social media open up new ways for collaboration and discussion. One of the characteristics that warrant concern is that with the widespread use and a range of social media, information posted on social media sites may remain there permanently. Another characteristic of concern is the replicability of material; this means that content can be copied, shared and even modified and shared. The characteristic of accessibility is also important; social media can be used anywhere, at any time, where an internet connection is available. Therefore, the use of social media and how it will affect the society is a medium that facilitates the interface between the individuals and communicating online and in real-time. The greatest advantage that the internet and the new media technologies offer is the ability to allow people to assemble even at a distance and communicate with numerous individuals at the same time in an inexpensive manner. In this regard Seargeant and Tagg (2014) highlight that one of the results of the rise of social media sites such as Facebook is that they have transformed the ways in which people can interact. Resultantly, it is important and beneficial to NGOs to use social media and to engage the society. Table 1 identifies the specific theme and significant quotes identifying the specific attribute.

\begin{tabular}{ll}
\hline Theme & Significant quote \\
\hline Immediate feedback & Social media has changed the way people communicate. \\
Two-way communication & Social media has the potential to educate, inspire, and engage others. \\
Convenient & Social media is informing and educating the public about issues, to publish \\
Easy to use & activity information or call people's attention to the NGO. \\
& Public relations practitioners participate in formal and informal communities \\
& or information and support networks where information is exchanged. \\
& Participants share their experiences of NGOs to benefit other activities, thereby \\
& creating information that is discovered and used by other communities. \\
& Public relations engage with information online to learn how to care for their \\
& NGOs and to deal with the practical aspects of challenges, as well as to realign \\
& their communication strategies to match the reality.
\end{tabular}

Table 1: Attribute 1 - Global Perspective

\section{Uses of social media for public relations}

The essence of social media is to focus and facilitate participating and interaction of the community with the business (in this case NGO) (Seageant and Tagg 2014:4). According to the literature (Graham and Dutton 2014: 349), unlike traditional media, social media is less hampered by time and space boundaries. This means that anyone, anywhere, can participate in a discussion online only if one has 
access to technology. Social media gives public relations the opportunity to connect, with other peers, in any region throughout the world. The success of using social media for communications is to broaden it to reach new audiences, to deepen relationships with existing audiences, to wage campaigns to respond quickly to events as well as to raise funds in ways that were not possible in the past.

The respondents indicated that through the use of social media they were able to reach out to people and disseminate information. The research findings indicated that practitioners in NGOs were using social media as communication tools to engage with different stakeholders. According to the interviewees the measure of success for any social media tool should be to allow engagement with internal and external stakeholders by facilitating the following aspects:

- Interaction;

- Disseminating information;

- $\quad$ Building relationships; and

- Enhance two-way communication.

Although Waters et al. (2009) pointed out back in 2009 that NGOs are using social media sites to support their public relations activities internationally, the interviewees pointed out that in South Africa this is not the case, albeit that it is seven years later. From the interviews, it was evident that the use of social media is not a general practice in South Africa's NGOs. Concerns were raised that social media initiatives in NGOs should form part of the wider communication strategy to become effective. The results indicated that the key uses of social media for public relations in NGOs are:

- Social media provided information on a range of conditions to the public relations practitioners;

- Social media allows information to be presentedso that passion and commitment to the organisations strategies and goals can increase;

- Social media platforms can facilitate dialogue between public and the practitioners;

- Social media can be used to recruit the youth, and collect information;

- Social media can be used to resolve and improve conflict and reach resolution;

- Through social media organisations can ensure that publics are kept aware of their activities and interact dialogically; and

- Social media are critical tools that an organisation can use to listen to stakeholders such as volunteers, and donors.

These findings revealed that although the interviewees felt that there was a noticeable improvement in the use of social media in NGOs, it requires public relations practitioners to think on a wider scale. There is also no place for a public relations practitioner who wants to play the traditional role by only writing text copy for release or print. Public relations now have to learn the skill of social media, adapt their style of information dissemination to fit the social media platform, and also know how to complement online platforms with traditional media; mere duplicating is not acceptable anymore. Table 2 identifies the specific theme and significant quotes identifying the attributes.

\begin{tabular}{ll}
\hline Theme & Significant quote \\
\hline Communication enabler & Social media provide information on a range of issues, \\
New supporters & $\begin{array}{l}\text { informing and educating the public about NGO } \\
\text { activities. }\end{array}$ \\
$\begin{array}{l}\text { Collaboration tool } \\
\text { Organisation promotion }\end{array}$ & $\begin{array}{l}\text { Social media provide information on mission, history } \\
\text { and organisational structure. }\end{array}$ \\
Fundraising & Social media encourage and facilitate dialogue \\
Responsiveness & between PR and public on donations and fundraising. \\
Transparency & Through social media, we have been able to talk with \\
Community engagement & other NGO member's online, collect information get \\
& experience and opinions about a subject. \\
& Social media used to form networks, to promote, \\
& educate, and to thecampaign. \\
\hline
\end{tabular}

Table 2: Attribute 2 - Uses of social media for public relations in NGOs 


\section{Benefits of social media for public relations}

Social media benefits refer to inexpensive, conversations are recorded, and immediate feedback is possible. The findings indicate that NGO organisationsare using social media to promote, engage, recruit, create networking, share information, knowledge and build relationships with various stakeholders. Social media itself is a communication platform that calls for participation, the initial action of joining the social networks indicates that the person partook in the media; keeping the audience interested and active then becomes the challenge. The research findings revealed the following are some benefits to NGOs of using social media:

- Increasing NGOs access to its audience and different stakeholders;

- Allowing NGOs to adjust communication quickly, where necessary;

- Increasing the speed of different stakeholders' feedback and input;

- Reaching specific audiences international and youth on specific issues;

- Improving the accessibility of NGOs' communication;

- Encourage transparency in online communication when advocating organisations' cause; and

- Improving the long-term cost effective relationship with volunteers, supporters, sponsors, and donors regarding activities.

Such participation results in the creation of communities online between users of social media. From the interviews the following needs were identified among the public relations practitioners in NGOs:

- Guidance on best practice use of social media; give brief examples of where such social media tools are used in NGOs;

- Understand the context before entering the conversation for example, is there a good reason to make a comment or respond;

- To provide more training torealise the potential benefits and risks associated with these tools;

- To provide a standard introductory overview of the social media tools that are most likely to be relevant in a South African NGO environment, for example, be ethical; and

- $\quad$ The code of conduct for employees should be respected and considered as the guiding rule.

Table 3 identifies the specific theme and significant quotes identifying the attribute.

\begin{tabular}{ll}
\hline Theme & Significant quote \\
\hline Enhancing relationships & Social media is more available because of anonymity, engagement, \\
Knowledge sharing & and connectedness. \\
Easy communication & Social media help promote NGOs image, programs, and services \\
Technology discovery & they offer to the community, such as social and emotional support. \\
Networking & Benefits of social media for NGO increase accessibility and \\
Peer-to-peer communication & widening access. \\
Transparency & Social media to increase funds, volunteers or community \\
Organisation promotion & engagement. \\
& The benefit of social media for NGO increase content and tailored \\
& information through newsletters, images or videos potential to \\
& influence policy and increase interactions with others. \\
\hline
\end{tabular}

Table 3: Attribute 3 - Benefits of social media for public relations in NGOs

\section{Limitations of using social media for public relations}

Research conducted by the Southern African NGO Network (2010) concluded that many NGOs have little information communication technology (ICT) capacity to and infrastructure, the contributing factors in this regard are the cost of ICT services, unreliable service providers, changing operating environment, ignorance, lack of strategic direction and lack of training and support.This has resulted in the uneven adoption of social media in the NGO sector. The main problem encountered by the participants was balancing social news and work news. Participants indicated that the disadvantages of social media are that anyone can join the social media sites such as Facebook and comment and partake in discussion and online conversation, but it does not guarantee that all the views contribute to NGO activities. Anyone can open and register on a Facebook page; theorganisation does not have control over social media content. The participants indicated that the limited resources, money, and knowledgeable 
staff definitely has an impact on public relations introducing social media for internal and external communication as it is more demanding to manage social media sites.

From the interviews the greatest challenge faced by South African NGOs is that of poverty reduction, creating jobs and reducing inequality. South African NGOs require social media policy that responds to the changing times and at the same position public relations practitioners to compete effectively on a global stage. Challenges regarding the slow uptake of social media were identified: threatened by new technology, fear of using social media, impact on reputation, social media seen as a waste of time. These challenges are discussed in more detail below:

- Threatened by new technology. The research participants indicated a need for more planning to use social media platforms. A need was also detected for social media tools versus spontaneous communication, and also the credibility of the NGOs' communication are important considerations towards ensuring interaction in social media platforms.

- Fear of using social media. A lack of resources was indicated. Computers, and other resources (including stationery) and time at work are reserved for NGOs related activities. Although some participant indicated that they fear using social media, others expressed serious concern when participants have to register too many personal details online many become hesitant to participate in the online community.

- Impact on reputation. A need for social media guidance was highlighted not only for public relations departmentbut also for the employees in the organisation. Such guidance should include: relevancy of its content, appropriate technology, and the relationships formed within that community benefits also contribute to the NGOs' sustainability.

- Social media are seen as a possible waste of time. The participants specified that respecting the time would assist with ensuring that personal online activities do not interfere with their work or duties.

- $\quad$ Risk associated with using social media. The research participants voiced a need forfamiliarising themselves with the content of disclosure on social media. Other participants expressed a serious need before an organisation uses social media it is imperative first to do an analysis of online communities so as to ascertain what meet the needs of the organisation. The research findings revealed that needs analysis, the demographics, access to the online and the objectives are all important.

The research findings stressed quality concerns, lack of reliability, unidentifiable authors, regulations, and policy not respected to validate the accuracy of information. The limitations of social media mentioned above are also confirmed by Van Zyl (2009), indicating that the large volume of information available through social media has the possibility for inaccuracies posted on sites challenges when validating information. Table 4 identifies the specific theme and significant quotes identifying the attributes.

\begin{tabular}{|c|c|}
\hline Theme & Significant quote \\
\hline Lack of understanding & Social media is informal and people talk freely, this way they hide \\
\hline Lack of resources & behind the screen, there is no hierarchy, they are in the comfort \\
\hline Lack of open communication & zone to express their feelings and attitudes. \\
\hline Lack of embracing social media & Social media can be a communication channel where skills and \\
\hline Lack of skills & interest can be identified because people may share more about \\
\hline Non-secure platforms & themselves, but lack reliability. \\
\hline Infrequent use & Threatened by new technology, fear of the unknown, risk of \\
\hline Technological change & disclosing personal private information online. \\
\hline Reputational risk & Quality concerns of social media information. \\
\hline Internet and email use policy & Lack of confidentiality and privacy impact on reputation. \\
\hline \multirow{4}{*}{$\begin{array}{l}\text { Comprehensive 'how to guide' to set up } \\
\text { accounts online }\end{array}$} & Risk associated with communicating incorrect, harmful \\
\hline & information online. Social media is seen as a possible waste of time. \\
\hline & $\begin{array}{l}\text { Too much information on social networking site NGOs can't } \\
\text { handle. }\end{array}$ \\
\hline & Not sure how to apply information found online correctly. \\
\hline
\end{tabular}


Not sure which certain social media technologies are effective to use in NGO for behaviour change.

Table 4: Attribute 4 - Limitations of using social media for public relations in NGOs

\section{Discussion of results}

The research interviews and the literature in this review provided evidence that social media is a communication platform to share opinions, ideas, insights, experience, and perspective. This relates to Weber (2009) who suggests and view social media as online places where people with a common interest can gather to discuss issues. From the research findings, it became evident that public relations practitioners are subjected to various challenges and experience of using social media in the NGO sector. There are a few prominent reasons why non-government organisations are slow to implement this new technology of social media for internal and external communication According to the Southern African NGO Network (2010) these limitations are:

- Lack of technology;

- Lack of budget;

- Quality concerns;

- Lack of management understanding;

- Social media poses significant risk to NGOs' reputation;

- $\quad$ Everyone is a producer of news;

- Lack of reliability of information due to online fake news;

- Regulations not known, understood or enforced; and

- No training in how to use social media technologies.

The literature review and results have shown that the public uses social media for various purposes such as to disseminate information, share experiences, comment on events, even to collect data and also to educate. However, many NGOs have limited internal social media capacity and infrastructure to compete with private enterprise. NGOs face numerous challenges in keeping up with the rapidly changing technologies while the results indicated difficulty towards adopting social media as public relations tool. Another issue is the unreliability of information of the information online. NGOs have limited resources, money, and knowledgeable staff which severely hamper their ability to create and execute an effective social media campaign. This research finding is also confirmed by Wright and Hinson (2010) who indicated that meaningful gaps exist when implementing social media in public relations. Therefore, social media tools remain informal, the information is unregulated, used for sharing and promotion; this means that there are almost no rules, a lack of clear social media strategies, and that difficulty in measuring the success of social media exists. In support, recent research reported to date there is limited evidence from public relations studies about the state of social media in the South African NGO sector (SA 2013). This South African Government Gazette also states that social media could be a useful mechanism for knowledge transfer. Unfortunately, in practice, implementation of social media in NGOs is limited due to a lack of time and technological skills.

Already in 2009, the South African Government Gazette (SA 2013) asserted that the South African government should approve the founding of an information society and to address public access to ICT facilities. In this regard, Kaplan and Haenlein (2010) stated that organisations should start using social media to improve their social presence, facilitate the social media to enhance closeness in synchronous face-to-face communication and create user generated content to improve communication between public relations practitioners and the public served by NGOs. To do so, Seargeant and Tagg (2014:5) suggested that a technically focused approach to the social media as a "web-based service "should allow individuals to construct a public or semi-public profile on social media. Additionally, articulation of participants' internal and external to the organisation should be able to share information (Kellerman 2014: 128). Social media use in public relations shows an increasing trend. However, the progress is slow, and NGOs still struggle to be fully accepted by their using social media as a communication tool. These researchers' views have been confirmed by the empirical results of this study. The interviews revealed that social media has benefits for public relations in NGOs. However, it is not widely implemented as a communication tool. 
Organisations can play meaningful roles in identifying the relative effectiveness of the different applications of social media in communication (Skinner et al. 2010). The interviewees indicated that their primary use of social media is interactions with public, facilitating, and sharing and obtaining information. This use is limited as practitioners do not embrace and adapt to the new social media challenge such as making time and learning technological skills. Furthermore, the NGOs do not assist their employees in achieving effective of social media use; hence an NGO will find it increasingly difficult to attract and retain the capable and motivated employees.

NGOs have to improve their technological advances to provide more opportunities to use social media in the future, especially between public relations and diverse stakeholders. Public relations in NGOs are required to embrace new technology and to fully train personnel to maximise the uses of social media in public relations communication in NGOs. However, the interviewees indicated that NGOs still have a long way to go before social media can be fully embraced and implemented in the NGO sector (World Wide Worx 2014).

The NGO sector should, furthermore, create the most suitable mechanisms to monitor and enhance the quality and reliability of public relations communication for using social media. To be effective, public relations should play a meaningful role by supporting initiatives that form part of a wider communication strategy, supplementing than replacing traditional communication platforms. Building awareness about the risk of sharing confidential and private information online and educating users is the utmost important (Graham and Dutton 2017). Public relations practitioners in NGOs should do a thorough situation analysis and plan the integration of social media before they implement it in their public relations campaign.

From the results, it was also evident that a need exists for an adequate support system for public relations practitioners in the South African NGO sector. The interviewees indicated that the full potential of social media could only berealisedby effective support in the employee-manager professional relationship. Interpersonal communication could result in two-way communication as well as creative and constructive collaboration with co-workers (Flynn 2012). Implementing social media and information technology can facilitate development activities such as education, communication and public relations in NGOs. Organisations that do not support employees to implement social media could adversely affect important conversations with interested publics and events among communication parties.

The research findings also identified gaps that need to be addressed. The impact of peer-topeer support, general public support, and support to public relations professionals are needed to enhance their interpersonal social media communication. This supportive view is confirmed by Wilcox, Cameron and Reber (2015) who stated that, in a changing environment, public relations is not seen as publicity and one-way communication, but rather as a complex and dynamic process of negotiation and compromise with some key audiences which are called publics.

Most NGOs do not have a technology plan in place. Social media has an impact on behaviourchange, and NGOs struggle to find a balance based on the consequences of not employing technology effectively in the organisation. Awareness of the need for such a plan needs to be emphasised so that more NGOs consider implementing social media plan within their respective organisations. The research finding is also confirmed by Stokes (2009) indicating the social media must be implemented with diligence and dedication to ensure that each organisation gains the necessary benefits that can improve communication and help employees distribute information, work together and solve problems rapidly. Social media need to aid the NGOs to achieve the purpose of their very existence, which is to further their aims and plan of action and to help those who need their assistance.

A major benefit of social media for NGOs' communication is the accessibility and widening access of NGOs information to various population groups regardless of age, education, race or ethnicity and locality compared to traditional communication methods. Research findings suggest the need for ongoing scrutiny regarding equality of access and effectiveness of social media for different users. The research findings are confirmed by Wilcox et al. (2015) and Seargeant and Tagg (2014) who observed that sharing, connecting, commenting and relationships are the building blocks of social media.

The research findings stressed regulatory, and security issues must be addressed to pave a way forward for best-practice that allows the benefits of social to be utilisedbut still protect the 
employee's privacy. The principle of regulatory issues is also confirmed by Flynn (2012), highlighting that the most effective way to manage social media is to implement rules and policies supported by comprehensive training and enforced by technology tools. Apart from the principles the important requirements in using social media were cited as transparency, disclosure, honesty, ethics, and measurement (Macnamara 2010). The following steps could be employed to ensure that public relations and employees in NGOs are aware of how to manage risks associated with this new kind of technology (Leach 2015; Torres 2014)):

- The employers should provide a standard personal responsibility for PR in NGOs;

- An introductory overview of the social media tools that are available and that are most likely to be used and relevant for the South African NGO context should be explained;

- Details of guidance in best-practice use of social media in NGOs should be communicated to all employees;

- Education and training must be valuable in tailoring education to meet the needs of population groups, considering personality traits, age, and gender; and

- $\quad$ The employees should be made aware of the potential benefits and risks associated with using social media tools.

\section{Conclusion}

Globally, it is evident that social media brings a new dimension to public relations practice. Social media tools present opportunities for collaborative public relations but implementing these tools in NGOs come with unique challenges. Social media offers a platform used by the public relations professionals, different stakeholders to communicate about NGO issues with the possibility of improving NGOs' activities. Publicly available social media sites such as Facebook or Twitter are providing public relations with attractive options for meeting these objectives. Although there are benefits to using social media for public relations communication in NGO, the information needs to be monitored for quality and reliability for user's confidentiality and privacy to be maintained. Social media is a powerful tool, which offers collaboration between users and is a social interaction channel for a range of individuals. Therefore it is of paramount importance that organisations need to recognise and understand the social media landscape and develop strategies that are suitable and be aware of what others are doing online and act accordingly. These social media sites are widely available to employees and public relations practitioners with internet access and have established online communities and networks without costs. Thisclearlyhighlights that social media has benefits for public relations communication but the long-term effects are not known. Developing social media theoretical guidelines is an important first step for public relations practitioners considering using social media as a key enabler for responsibly and effectively embracing social media tools.

It is also important to take note of the findings of this research conducted on uses, benefits and limitations of social media in the NGO sectorand to subsequently develop strategies and plans to effectively address these social media challenges to ensure the successful and sustainable policies to guide their efforts as well as for others to draw on or learn from.

\section{Limitations and direction for further studies}

This study poses a number of limitations that should be taken into consideration before the results are operationalised. Where applicable, the direction of further study that is relevant to a limitation is then presented. The limitations (and areas of further study) are:

- $\quad$ The respondents reported on South African NGOs. This means that the results pertain only to South Africa. Although similar observations are evident throughout Africa, this should be Confirmed by further research into the rest of the continent.

- $\quad$ The results provide a snapshot of current affairs of social media and public relations in NGOs. This could change at any time if strategic goals or policy change in the government sector. Resultantly, future studies should confirm if the findings in this study is still relevant in the near future. This is important prior to initiating specific activities to improve the use of social media in public relations. 
- Although the principle of saturation was used to determine the number of respondents, the reach of qualitative studies is limited by its relatively small samples. An exciting avenue for further research would be to use the findings of this study to compile a questionnaire that can capture a large number of quantitative data to analyse. This could further shed some light on the use of social media in public relations.

\section{Summary}

The empirical research reflects and confirms that opportunities for future research exist. Social media is a fast developing and changing the subject and therefore continued research should be conducted by public relations using a range of methodologies on how social media can be usedas a communication channel in NGOs. Social media has become such an important tool; public relations need to know exactly who to target with their messages. Before an organisation uses social media, it is imperative that public relations understand applications and online communities and after that meet the needs of the organisation. This could be a valuable case study of how technology could be successfully implemented as an internal and external communication channel to enhance the public's engagement. Continued research should be conducted by relevant communication departments (public relations practitioners, marketing) to increase awareness of the challenges and risks that the public still experienceswhen using social media in the NGO sector from a South African perspective.

\section{References}

Al-Deen, H.S.N. \& Hendricks, J.A. 2012. Social media usage and impact. Lexington, KY: Lexington Books.

Business Directory. 2017. Social media. From <http://www.businessdictionary.com/definition/socialmedia.html>(Retrieved April 23, 2017).

Creswell JW 2013. Qualitative inquiry and research design: Choosing among five approaches. $3{ }^{\text {rded. London: }}$ Sage.

CNN News. 2017. Facebook is closing on 2 Billion users. From

<http://money.cnn.com/2017/02/01/technology/facebook-earnings/>(Retrieved April 21, 2017).

Erasmus, L. 2012. The increased application of social media in the South African public relations industry. Pretoria: University of Pretoria.

Flynn, N. 2012. The Social Media Handbook: Policies and best practices to effectively manage your organisations, social media presence, posts and potential risks. San Francisco, CA: Wiley.

Gorman, L.\&McLean, D. 2009. Media and society into the $21^{\text {st }}$ Century: A historical introduction. $2^{\text {nded. }}$ London: Wiley-Blackwell.

Graham, M. \& Dutton, W.H. 2014. Society and the internet: How networks of information and communication are changing our lives. Oxford: Oxford University.

Graham, M. \& Dutton, W.H. 2017. Internet studies: A critical new field in social science. From

$<$ https://billdutton.me/category/internet-studies/>(Retrieved April 24, 2017).

Kaplan, A.M. \& Heinlein, M. 2010. Users of the world, unite! The challenges and opportunities of social media. Business Horizons, 53(1):59-68.

Kellerman, A. 2014. The interne as second action space. Oxon, NY: Routledge.

Leach, A. 2015. 15 ways NGOs can attract positive media attention. From

<https://www.theguardian.com/global-development-professionals-network/2015/mar/03/ngospositive-media-attention-communications-pr>(Retrieved December 10, 2016).

Mayfield, A. 2008. What is social media? From

<http://icrossing.co.uk.fileadmin/uploads/ebooks/What_is_social_media_icrossing_ebook.pdf (RetrievedApril4, 2013).

Macnamara, J. 2010. The 21stcentury Media revolution emergent communication Practices. New York, NY: Peter Lang.

Nchabeleng, G. 2016. Developing a policy guideline for social media in public relations practice at selected nongovernmental organisations in Gauteng. PhD thesis. Potchefstroom: North-West University.

Neuman, W.R. 2010. Media, technology and society theories of media evolution media, technology and society theories of media evolution. Ann Arbor, MI: University of Michigan. 
O'Reilly, T. 2005. What Is Web 2.0? Design patterns and business models for the next generation of software. From <http:/ / oreilly.com/web2/archive/what-is-web-20.html>(Retrieved July14, 2010).

Patel, L. 2010. The rise of social media. From <http://www.astd.orgITD/Archives/2010/July/ free/1007.TheRiseOf.htm> (Retrieved May 19, 2015).

Patel, T. 2016. The role and influence of social media on the modern PR industry. From $<$ http:// www.prmention.com/blog/the-role-and-influence-of-social-media-on-the-modern-prindustry/>(Retrieved April 24, 2017).

Pindar, B. 2017. 12 social media and digital trends for business in 2017. From

<http:// www.northernlightspr.com/12-social-media-and-digital-trends-for-business-in2017/>(Retrieved April 24, 2017).

Rathore, D. 2016. What is Web 2.0? From <https://www.znetlive.com/blog/web-2-0/>(Retrieved April 10, 2017).

Rettberg JW 2014. Blogging: Digital media and society series. Cambridge: Pearson.

Southern African NGO Network 2010. State of ICT in the South African NGO Sector 2009. From $<$ http://www/ngoplus.org> (Retrieved March14, 2014).

Seargeant, P. \& Tagg, C. 2014. The language of social media: Identity and community on the Internet. New York, NY: Palgrave McMillan.

Smithsonian Museum of Natural History. 2010. Gulf oil spill. From <http://ocean.si.edu/gulf-oil-spill> (Retrieved April 10, 2017).

South Africa (SA). 2013. Government Gazette.(No. 32420). Pretoria: Government Printer.

Stokes, R. 2009. eMarketing: The essential guide to online marketing. $2^{\text {nd }}$ ed. New Delhi: Shumani.

Supa, D.W. 2014. A qualitative examination of the impact of social media on media relations practice. Public Relations Journal, 8(2):1-11.

Skinner, C., Von Essen, L., Mersham, G. \& Motau, S. 2010. Handbook of public relations. $9^{\text {th }}$ ed. Cape Town: Oxford.

Torres, J. 2014. 8 Steps to protecting the organization against social media risks. From

<https://www.linkedin.com/pulse/20140430072954-6260457-8-steps-to-protecting-against-social-mediarisks>(Retrieved April 20, 2017).

Waters, R.D. 2007. Non-profit organisation use of the Internet, a content analysis of the communication trends of the Internet of the philanthropy of 400. Non-profit Management and Leadership, 18(1):59-76.

WebAppRater. 2010. 7 key features of Web 2.0/ From <http://www.webapprater.com/general/7-keyfeatures-of-web-2-0.html>(RetrievedApril 20, 2017).

Weber, L. 2007. Marketing to the social web: How digital customer communicates build your business. Hoboken, NJ: Wiley.

White, A. 2014. Digital media and society: transforming economics, politics and social practices. New York, NY: Palgrave MacMillan.

Wilcox, D.L., Cameron, G.T. \& Reber B.H. 2015. Public relations: strategies and tactics. $11^{\text {th }}$ ed. Harlow: Pearson.

Wright, D.K. \& Hinson, M.D. 2010. How new communications media are being used in public relations: A longitudinal analysis. Public Relations Journal, 4(3):1-27. 